\title{
MOLECULES, MORPHOLOGY, AND AREEA CLADOGRAMS: A CLADISTIC AND BIOGEOGRAPHIC ANALYSIS OF GAMBUSIA (TELEOSTEI: POECILIIDAE)
}

\author{
Charles Lydeard, ${ }^{1,4}$ Michael C. Wooten, ${ }^{2}$ and Axel Meyer ${ }^{3}$ \\ ${ }^{1}$ Aquatic Biology Program, Department of Biological Sciences, University of Alabama, \\ Box 870344, Tuscaloosa, Alabama 35487, USA \\ ${ }^{2}$ Department of Zoology and Wildlife Science, Auburn University, \\ Auburn, Alabama 36849-5414, USA \\ ${ }^{3}$ Department of Ecology and Evolution, State University of New York, \\ Stony Brook, New York 11794-5245, USA
}

\begin{abstract}
Researchers investigating historical biogeography rely on taxon cladograms to infer the relationships of different areas of endemism. Unfortunately, systematists are often faced with many equally parsimonious taxon cladograms from a single data set or conflicting phylogenetic hypotheses from independent data sets. We present an analysis of congruence between two conflicting phylogenetic hypotheses of the poeciliid fish genus Gambusia, one based on mitochondrial DNA sequences and the other based on morphological characters. We explore how different phylogenetic hypotheses alter interpretations of area relationships and propose a set of area relationships for the genus. Furthermore, we compared the area relationships depicted for Gambusia with that of two Middle American fish genera (Xiphophorus and Heterandria) with similar distributional limits. Our analysis revealed areas of congruence among taxa from nuclear Central America but areas of incongruence among taxa from the Panuco basin and North American components. We discuss the implications of our findings in light of conventional hypotheses regarding Caribbean biogeography. This study illustrates the importance of considering alternative phylogenetic hypotheses fully before attempting to interpret the biogeographic history of a taxon or region. [Historical biogeography; Caribbean biogeography; phylogeny; Gambusia; Poeciliidae; congruence; area cladograms.]
\end{abstract}

Researchers investigating historical biogeography attempt to discover the spatial distributional patterns exhibited by life and explore possible mechanisms that could have produced such patterns. Patterns of spatial distribution or area relationships are constructed by replacing terminal taxon names on a cladogram with the distributional limits of the respective taxon (see Platnick and Nelson, 1978; Nelson and Platnick, 1981; Humphries and Parenti, 1986). Of course, before an area cladogram can be constructed, a taxon cladogram is needed. Ideally, there would be a single most-parsimonious taxon cladogram, with each taxon restricted to one particular area of endemism. Unfortunately, as Platnick (1981:223) observed, "nature is not usually so cooperative." Typically, problems arise, such as more than one equally parsimonious taxon

\footnotetext{
${ }^{4}$ E-mail: clydeard@biology.as.ua.edu.
}

cladogram, widespread or missing taxa, and redundant distributions.

Although there is considerable interest in examining the level of congruence exhibited among phylogenetic hypotheses derived from two or more independent data sets for the same group of organisms (e.g., Mickevich and Johnson, 1976; Mickevich, 1978; Miyamoto, 1983; Bledsoe and Raikow, 1990; Shaffer et al., 1991), few attempts have been made to examine congruence among area cladograms computed from independently derived taxon cladograms. One fish taxon, the genus Gambusia (Cyprinodontiformes: Poeciliidae), offers an excellent opportunity to evaluate not only the level of congruence exhibited by phylogenetic hypotheses derived from independent data sets but also the level of congruence exhibited by area cladograms derived from the different taxon cladograms.

The genus Gambusia comprises approximately 45 nominal species and is found 
throughout the southeastern United States, Mexico, Central America, the Greater Antillean Islands, and northern South America (one disjunct species) (Rosen and Bailey, 1963; Rauchenberger, 1989). Rosen and Bailey (1963) and Rivas (1963) independently proposed a classification of Gambusia. Their classifications differ considerably in the delineation of groups and in the assignment of species to groups (see Rauchenberger [1989] for a detailed historical review). Rauchenberger (1989) attempted to alleviate some of the taxonomic confusion and proposed a classification of the genus based on a cladistic analysis of morphological characters (Appendix 1).

Nearly all systematic studies of Gambusia and other poeciliids in general have relied on morphological characters that are almost exclusively from a single morphological character complex, the gonopodium (a secondary sexual modification of the anal fin of males used to transfer sperm) and its associated support structures (more than $60 \%$ of the characters Rauchenberger [1989] surveyed were from this source). These characters, however, may lack developmental independence and may be functionally linked, making it difficult to determine whether shared traits are due to a shared common ancestry or convergence and parallelism (e.g., Constantz, 1989).

Given the potential lack of independence of the morphological characters and the lack of concordance among the three most recent systematic studies of the entire genus (Rivas, 1963; Rosen and Bailey, 1963; Rauchenberger, 1989), we sequenced and analyzed mitochondrial DNA (mtDNA) sequence variation from 24 species of Gambusia and used the data to infer phylogenetic relationships among these taxa (Lydeard et al. 1995). The purpose of the present study was to measure qualitatively and quantitatively the congruence between a phylogenetic hypothesis based on the mtDNA sequences and a phylogenetic hypothesis based on our reanalysis of Rauchenberger's (1989) morphological data set. In addition, we present one way to obtain area cladograms from the morphological and molecular data sets when faced with the problem of numerous equally parsimonious taxon cladograms and compare the area cladograms from the two independent data sets to area cladograms generated from the two data sets combined. We also discuss the biogeography of Gambusia and compare the area relationships found for Gambusia with those for two Middle American fish genera, Xiphophorus and Heterandria, which were previously shown to exhibit congruent area relationships (Rosen, 1978, 1979; Platnick, 1981; Page, 1989, 1994).

\section{THE DATA}

Phylogenetic analysis of the Gambusia mtDNA and morphological data was done using the PAUP 3.1 software package (Swofford, 1993). A heuristic algorithm was employed to search for the most-parsimonious tree(s) using the following options: keep minimum trees only, collapse zero length branches, random addition of taxa with 10 replications, and swapping algorithm with tree bisection and reconnection. Belonesox belizanus, a monotypic genus, was used as the outgroup taxon (Rosen and Bailey, 1963; Rauchenberger, 1989; Meyer, unpubl. data). Bootstrap measures of stability (Felsenstein, 1985) for branches of the most-parsimonious trees were estimated with 200 iterations using PAUP. All consensus trees, agreement subtrees, area cladograms, and quartet statistics were generated using the software package COMPONENT 2.0 (Page, 1993).

\section{Phylogeny of Gambusia Based on mtDNA}

The mtDNA data are from 33 specimens representing 24 species of the three subgenera and eight species groups diagnosed for Gambusia (sensu Rauchenberger, 1989; see Appendix 1). Specific locality information and sources are provided elsewhere (Lydeard et al., 1995).

Lydeard et al. (1995) examined nucleotide variation for a 392-402-base-pair segment of the $5^{\prime}$ end of the cytochrome $b$ gene. Maximum parsimony analysis of the cytochrome $b$ sequences (137 variable sites, 105 of which were phylogenetically infor- 


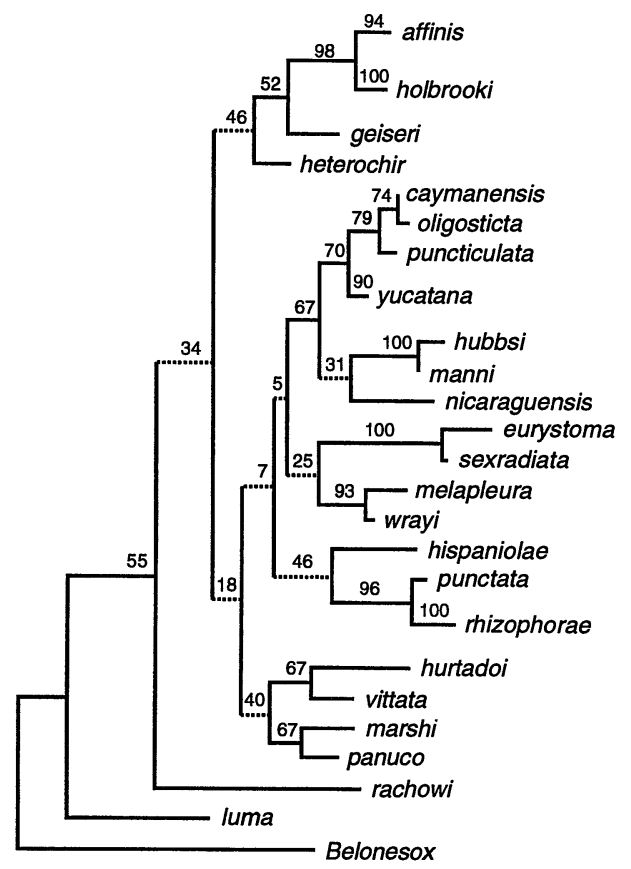

FIGURE 1. A cladogram of the single most-parsimonious tree for Gambusia derived from up to 407 base pairs of a segment of the mitochondrial cytochrome $b$ gene when weighting transversions four times over transitions (Lydeard et al., 1995). The percentage of 200 bootstrap replications is given for each node. Branches with bootstrap values of $>50$ are shown as dashed lines.

mative) resulted in a single most-parsimonious tree of 695 steps when transversions were weighted four times over transitions. This weighting strategy was employed to reduce the potential effects of saturation in the third codon position and represents the average transition/transversion ratio among Gambusia species. An identical tree was obtained for separate analyses when transversions were weighted five through eight times over transitions (Fig. 1). Details regarding transition/transversion ratios, intra- and interspecific percent sequence difference, and additional analyses are reported elsewhere (Lydeard et al., 1995).

\section{Phylogeny of Gambusia Based on Morphological Characters}

Rauchenberger (1989) presented an analysis of 62 morphological characters, the first six of which were used to assess the interrelationships of the tribe Gambusiinae. Because of the "lack of resolution in several areas of the cladogram" (1989:70) when all taxa and all characters were included, Rauchenberger chose to subdivide the data set into smaller matrices using only the characters she deemed relevant for a particular taxonomic level. Because this apparent lack of resolution warranted further scrutiny, we reanalyzed her data set with the following modifications: (1) the four data matrices (1989: tables 2-4) were combined into one matrix; (2) character 16 was not used because of inconsistencies in scoring among Rauchenberger's (1989) text, figures, and tables and because the character state even varied between the left side and right side of the same specimen; (3) we combined her characters 54 and 59 into our character 59 because they both represent the presence or absence of metacentric or submetacentric chromosomes; (4) character 58 was used (labeled 59 in her table 5); and (5) all multistate characters were treated as unordered because there are no data regarding the transformation series. Our data matrix of the 55 characters is shown in Appendix 2.

Analysis of the 55 morphological characters for the 24 species of Gambusia resulted in 18 equally parsimonious trees of 115 steps with a consistency index (CI) of 0.53 (excluding uninformative characters). A strict consensus tree of the 18 equally parsimonious trees is shown in Figure 2.

The phylogenetic hypothesis revealed by our reanalysis of Rauchenberger's (1989) morphological data differs from the classification she proposed (see Figure 2; Appendix 1). For instance, there is uncertainty in the monophyly of the subgenera Arthrophallus and Gambusia. Gambusia sexradiata and G. eurystoma are more closely related to the puncticulata + punctata species groups than to $G$. heterochir of the nobilis species group as Rauchenberger hypothesized. In addition, the nicaraguensis species group is either the sister group to the clade containing G. hurtadoi, G. geiseri, G. heterochir, G. holbrooki, and G. affinis or the sister group to the members of the subgenus 


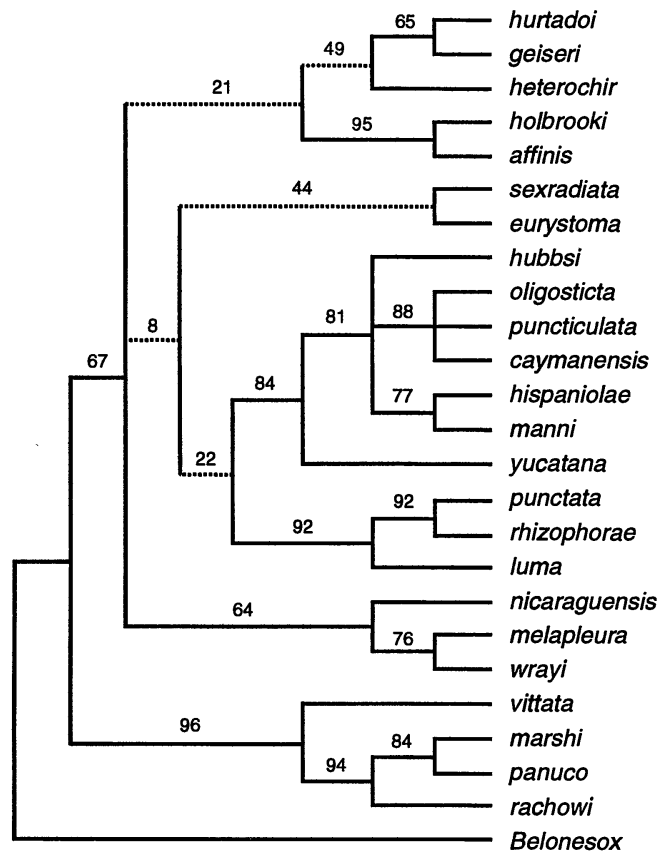

FIGURE 2. A strict consensus tree for 18 equally parsimonious cladograms for Gambusia based on 55 morphological characters of Rauchenberger (1989) modified and reanalyzed (Appendix 2). The percentage of 200 bootstrap replications is given for each node. Branches with bootstrap values of $>50$ are shown as dashed lines.

Gambusia. To be certain that this finding was not an artifact of our smaller sample size ( 24 species vs. 45 species), we repeated our analysis using all 45 species. This analysis resulted in $>6,800$ equally parsimonious trees (not shown), which reflected many inconsistencies similar to those found in our analysis of the 24 species.

\section{TAXONOMIC CONGRUENCE}

Taxonomic congruence is the degree to which two or more phylogenetic hypotheses based on independent data sets agree (Mickevich, 1978; Kluge, 1989). Typically, this measure involves a consensus cladogram generated from a comparison of the independently derived phylogenetic hypotheses.

A single most-parsimonious tree was obtained from the molecular data, and 18 equally parsimonious trees were obtained from the morphological data. Combining all 19 trees together to generate a consensus tree would confound between and within data set differences (Page, 1993). Mickevich and Farris (1981) suggested measuring the degree of disparity between the two most similar trees that can be found among two or more data sets. To determine which were the most similar morphological and molecular trees, we compared all possible pairs of trees from the two data sets and computed the number of taxa (leaves) that needed to be removed from each pair of trees to obtain identical subtrees (Finden and Gordon, 1985).

The molecular tree was most similar to morphological trees 1-6, 9-13, 15, and 16 with 14 leaves pruned versus 15 leaves pruned for the remaining trees. Given that the molecular tree was deemed equally similar to 13 of the 18 morphological trees based on the number of leaves pruned, we used quartet statistics (Estabrook et al., 1985) to attempt to further differentiate the pairs of trees. Quartet statistics compares all possible unrooted branching networks of four taxa derived from each of the topologies being compared and measures how often they are the same. We determined one measure of similarity: the DC (Do not Conflict) value. This statistic is identical to EA (Explicitly Agree) when the trees do not contain polytomies, as in the present study. DC is the proportion of possible quartets that did not conflict, and is expressed as

$$
\frac{s+r 1+r 2+u}{Q},
$$

where $s=$ number of quartets resolved and identical in both trees, $r 1=$ number resolved in tree 1 but not in tree 2, r2 = number resolved in tree 2 but not in tree $1, u=$ number unresolved in both tree 1 and tree 2 , and $Q=$ all possible quartets. The DC value for comparison of the molecular tree and morphological trees ranged from 0.57 to 0.63 ; the highest values were obtained in the comparison of the molecular tree with morphological trees 2, $9,10,11,12$, and $13(\mathrm{DC}=0.63, s=8034$, $r 1=0, r 2=0, Q=12,650)$. 
(a)

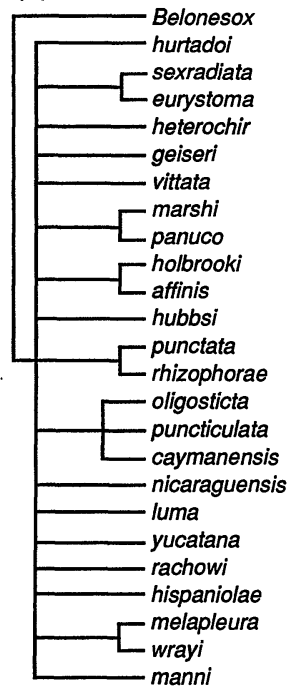

(b)

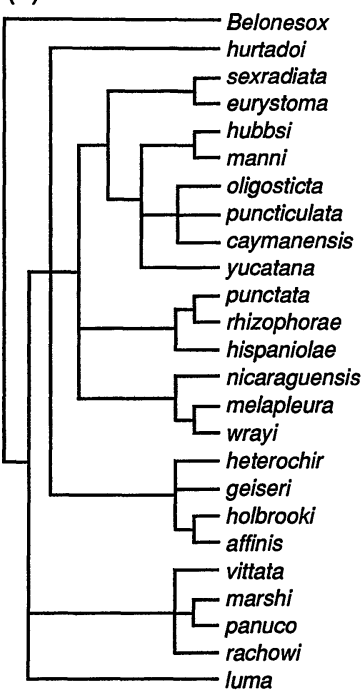

FIGURE 3. Strict (a) and Adams (b) consensus trees of the two most similar morphological and molecular trees for Gambusia.

A comparison of triplets (quartets with one member as the root of the tree), which is a more appropriate comparison for rooted trees (Page, 1993), yielded a DC of 0.67. These DC and EA values are lower than the average values $(\mathrm{DC}=0.85, \mathrm{EA}=0.71)$ reported by Bledsoe and Raikow (1990) in their study of congruence between molecular and nonmolecular data sets; however, they did find that as the number of taxa increased, congruence decreased. The only difference within each set of three morphological trees $(2,10,11 ; 9,12,13)$ was the alternative placement of $G$. caymanensis, G. oligosticta, and G. puncticulata in respect to one another (these three taxa have branches of length zero separating them). The two sets of three trees differed from each other in the placement of G. hubbsi. Strict and Adams consensus trees of the molecular tree and each of the six morphological trees $(2,10,11 ; 9,12,13)$ yielded identical trees (Fig. 3). The strict consensus tree (Fig. 3a) shows only topological patterns depicted in each fundamental cladogram (Kluge, 1989; Page, 1993). The following monophyletic groups were found in common: (G. sexradiata, G. eurystoma), (G.

(a)

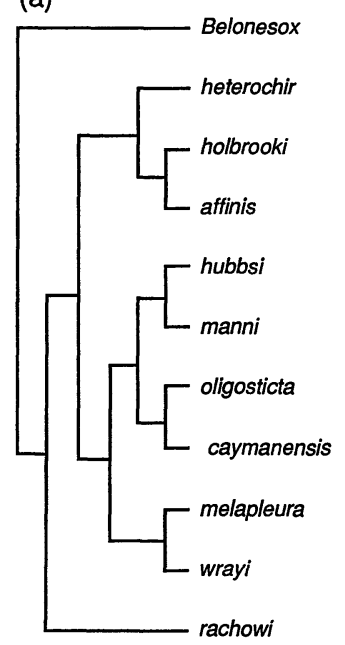

(b)

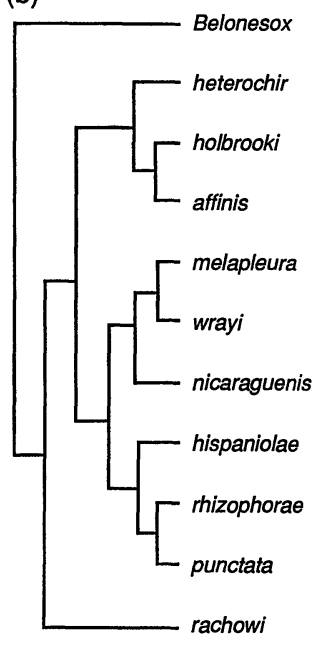

FIGURE 4. The greatest agreement subtrees between the Gambusia molecular tree and morphological trees 2, 10, and 11 (a) and the molecular tree and morphological trees 9, 12, and $13(\mathrm{~b})$. Fourteen taxa were pruned to obtain this identical pattern.

marshi, G. panuco), (G. holbrooki, G. affinis), (G. punctata, G. rhizophorae), (G. oligosticta, G. caymanensis, G. puncticulata), and (G. melapleura, G. wrayi). The Adams consensus tree (Fig. 3b) shows the intersection of the molecular tree and the morphological tree and reveals more structure between the two rival trees than does the strict consensus tree. The Adams consensus tree is useful for finding patterns in common when some taxa have very different positions in the two rival trees (Page, 1993). These patterns may not be evident in a strict consensus tree, which may depict relationships as a completely unresolved bush even though the only difference is the placement of one taxon (Swofford, 1991). The Adams consensus tree depicts more of the structure found in each of the cladograms based on morphological and molecular data.

The greatest agreement subtree (GAS) is the largest subset of leaves for which trees from each data set depict the same relationships (Finden and Gordon, 1985; Kubicka et al., 1995). Figure 4 depicts the GASs obtained when comparing the molecular tree with morphological trees 2, 10, 
and 11 (Fig. 4a) and 9, 12, and 13 (Fig. 4b). Each GAS required the pruning of 14 taxa. These GASs depict the same subgeneric relationships that Rauchenberger (1989) hypothesized: (Heterophallina(Arthrophallus, Gambusia) (see Appendix 1). However, this congruence is only realized after pruning 14 of the taxa from the data set.

\section{Character Congruence}

Miyamoto (1983, 1985) and Kluge (1989) have argued that the best estimates of phylogeny may be obtained by an integrative approach examining overall character congruence of a combined data set versus taxonomic congruence between analyses of independent data sets (e.g., Kluge, 1989). Although arguments against the combined approach have been made (e.g., Shaffer et al., 1991; Swofford, 1991), this approach may offer additional insights about the relative strengths and weaknesses of each independent data set (Hillis, 1987). A maximum parsimony analysis of the molecular and morphological data sets combined with transversions weighted four times over transitions and other characters equally weighted resulted in six equally parsimonious trees of 843 steps with a CI of 0.35 (excluding uninformative characters). A strict consensus of these six trees is shown in Figure 5. The strict consensus tree is less resolved than are the trees from either of the two data sets analyzed independently, reflecting the lack of congruence between the two data sets. Combining the two data sets resolves the tree in favor of the "strongest" information (Hillis; 1987). The molecular data support the placement of G. luma, G. rachowi, G. hispaniolae, G. yucatana, G. manni, G. hurtadoi, G. vittata, and G. sexradiata + G. eurystoma.

\section{BIOGEOGRAPHY OF GAMBUSIA}

Rosen's $(1975,1978,1979)$ landmark biogeographic studies of the Middle American and Caribbean taxa were based primarily on the freshwater fish fauna of the region. Unfortunately, despite numerous studies describing the distributions and derivations of the ichthyofauna of the Caribbean basin (e.g., Miller, 1966; Myers,

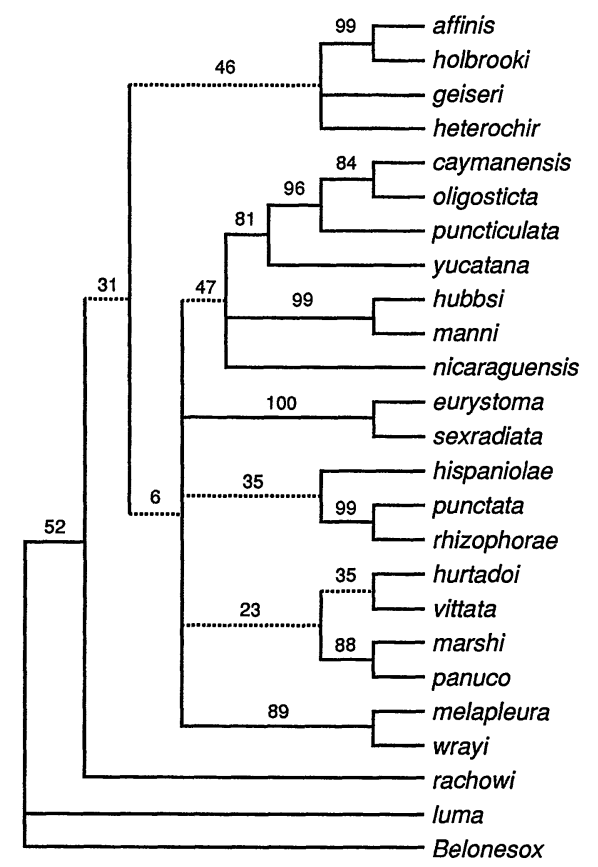

FIGURE 5. A strict consenus tree of the six equally parsimonious trees derived from the combined morphological and molecular Gambusia data. The percentage of 200 bootstrap replications is given for each node. Branches with bootstrap values of $>50$ are shown as dashed lines.

1966; Bussing, 1976, 1985; Lee et al., 1980; Briggs, 1984; Miller and Smith, 1986; Rivas, 1986; Smith and Miller, 1986; Rauchenberger, 1988; Burgess and Franz, 1989), there are few testable biogeographic statements derived from sound phylogenetic hypotheses of other monophyletic groups of fish.

We defined 16 areas of endemism based on the distributions of the taxa examined in this study (Fig. 6; Appendix 1) and previous zoogeographic studies of the ichthyofauna of the region (e.g., Rosen, 1979; Miller and Smith, 1986; Smith and Miller, 1986). Detailed distributional information for each Gambusia species was presented by Rauchenberger (1989). We performed a heuristic search to find the optimal area cladogram from the taxon cladograms using the optimality method provided in COMPONENT 2.0 (Page, 1993) with the following options: nearest-neighbor inter- 


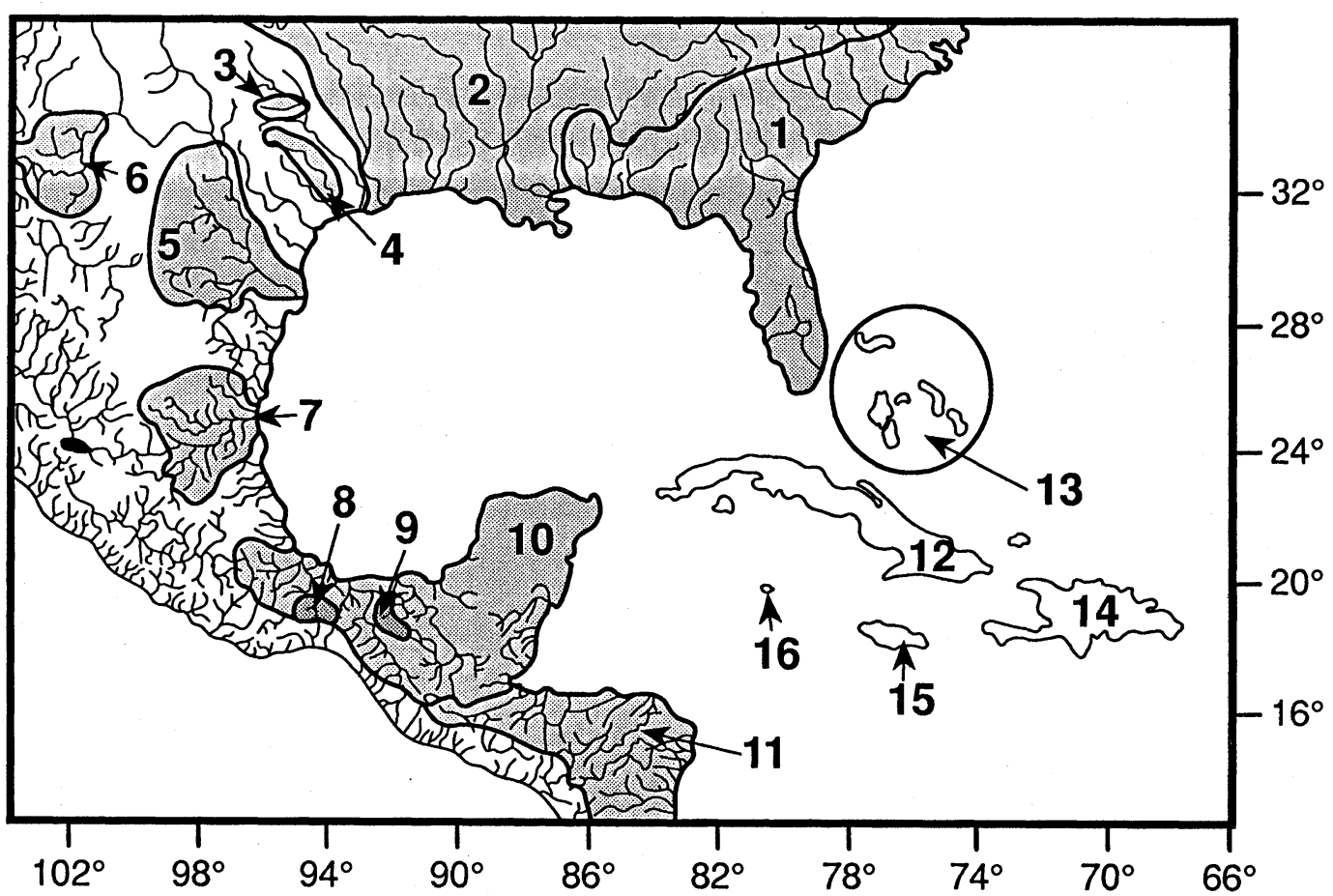

FIGURE 6. Areas of endemism based largely on the distributions of 24 Gambusia species included in the present study. 1 = southeastern (SE) USA; $2=$ south-central (SC) USA; $3=$ San Saba; $4=$ San Marcos; $5=$ Lower Rio Grande; 6 = Conchos; 7 = Panuco; 8 = Coatzacoalcos; 9 = Sulphur Springs; $10=$ Maya Block; 11 = Chortis Block; 12 = Cuba; $13=$ Bahamas; $14=$ Hispaniola; 15 = Jamaica; 16 = Grand Cayman.

changes and minimizing the number of leaves added (see Page, 1990a, 1990b, 1993). The optimality method does not suffer from the restrictions of conforming to the restraints of the algorithms for assumptions 0, 1, and 2 (Page, 1994). Assumptions 0,1 , and 2 represent three methods for constructing and comparing area cladograms; these methods differ in how they interpret widespread taxa and redundant distributions (Page, 1988). Because each equally parsimonious tree may infer different area relationships and because of the difficulties in inferring area relationships based on a consensus tree with polytomies, the area cladograms were based on each of the equally parsimonious dichotomous trees summarized in Figures 1, 2, and 5.

Analysis of all of the equally parsimonious trees derived from the molecular, morphological, and combined data sets may provide many possible sets of area relationships for each tree. We believe the best area cladogram for each set of area cladograms is the most resolved and hence informative one because it is the most falsifiable hypothesis. Some trees will no doubt produce more informative area cladograms than will others. Therefore, we will present the most informative area cladograms from each analysis. These area cladograms allow for many more rigorous tests of the generality of the pattern found for Gambusia than do less informative, unresolved hypotheses.

Analysis of the single tree based on molecular Gambusia data resulted in three equally parsimonious area cladograms. A strict consensus tree of these three area cladograms is shown in Figure 7 (the Adams consensus tree was identical to the strict consensus tree).

Analysis of the 18 trees based on mor- 


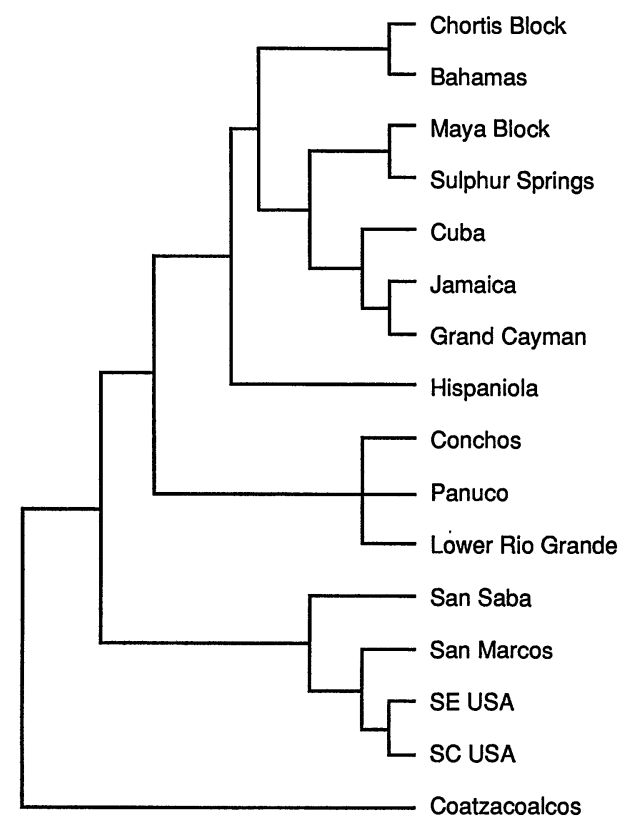

FIGURE 7. A strict consensus tree of the three most optimal area cladograms. computed from a heuristic search of the phylogeny of Gambusia based on molecular data.

phological Gambusia data resulted in 1-77 equally parsimonious area cladograms for each taxon cladogram: tree $1=11$ cladograms; tree $2=1$; tree $3=1$; tree $4=77$; tree $5=11$; tree $6=11$; tree $7=77$; tree $8=77$; tree $9=7$; tree $10=1$; tree $11=$ 1 ; tree $12=7$; tree $13=7$; tree $14=7$; tree $15=1$; tree $16=1$; tree $17=7$; tree $18=$ 7. The most informative area cladograms are from trees 2, 3, 10, 11, 15, and 16, which were identical (Fig. 8). All other trees were consistent with this pattern but were less resolved.

The primary difference between the area cladograms derived from the molecular data (Fig. 7) and those derived from the morphological data (Fig. 8) is the placement of Conchos, Hispaniola, and Bahamas. Using the two GASs (Fig. 4) for the morphological and molecular data sets to compute an area cladogram results in the patterns depicted in Figure 9. A single area cladogram was obtained from the GAS shown in Figure $4 \mathrm{a}$, and 15 equally parsimonious trees were obtained from the

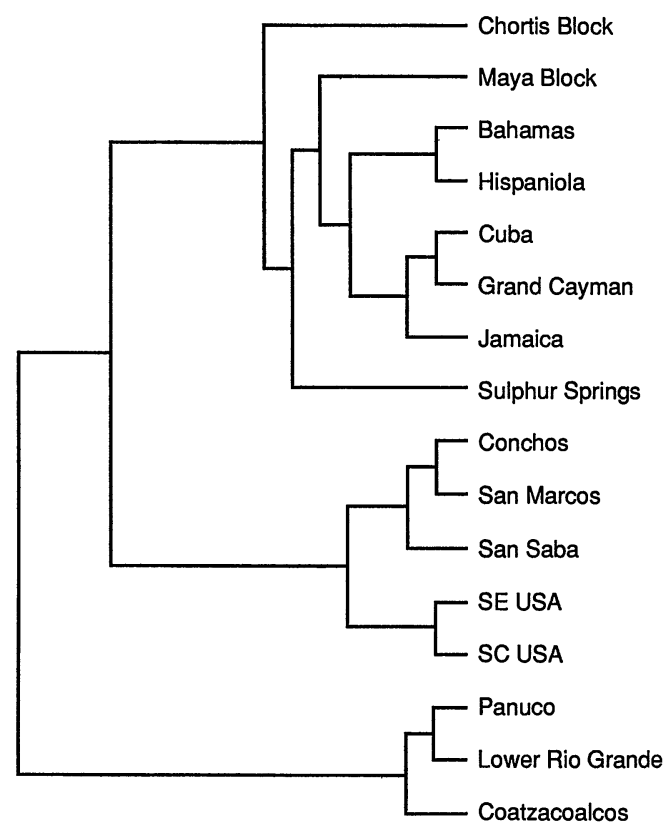

FIGURE 8. The single most optimal area cladogram computed from a heuristic search of Gambusia morphological trees 2, 3, 10, 11, 15, and 16. This cladogram represents the most informative set of area relationships found from the analysis of the 18 equally parsimonious morphological trees.

GAS shown in Figure $4 \mathrm{~b}$. The differences between the area cladograms (Fig. 9) are largely due to inclusion of different taxa from different areas.

Several area cladograms were computed from the analysis of the six equally parsimonious trees based on the combined morphological and molecular data sets (tree $1=15$ cladograms; tree $2=15$; tree $3=3$; tree $4=33$; tree $5=3$; tree $6=39$ ). The most informative area cladograms based on the combined data sets are from trees 3 and 5. A strict consensus tree of the three area cladograms obtained from tree 3 is shown in Figure 10. The area cladogram derived from the analysis of tree 5 differs from the cladogram derived from tree 3 in depicting Hispaniola as the sister to Cuba. Area cladograms from trees 1, 2, 4 , and 6 are similar to those from tree 3 but are less resolved. The most informative area cladogram based on the two data sets combined (Fig. 10) is thought (like the tax- 
(a)

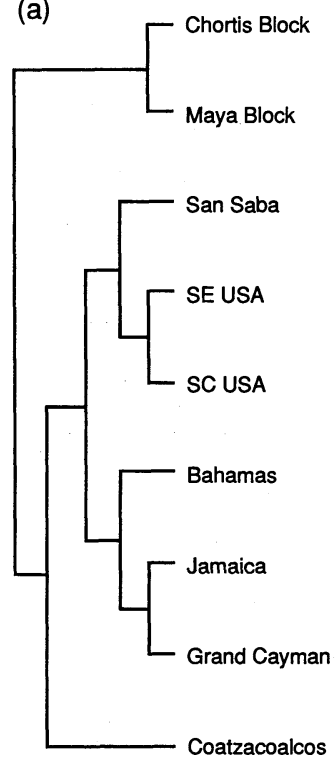

(b)

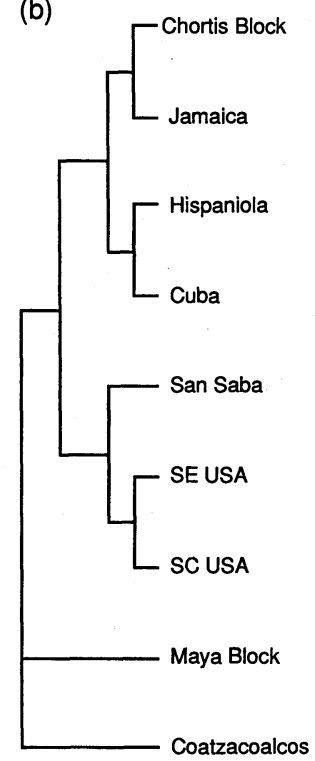

FIGURE 9. The single most optimal area cladogram (a) and an Adams consensus tree of the 15 most optimal area cladograms (b) computed from a heuristic search of the greatest agreement subtrees shown in Figures $4 \mathrm{a}$ and $4 \mathrm{~b}$, respectively. A strict consensus tree of the 15 most optimal area cladograms is completely unresolved (not shown).

on cladogram) to reflect patterns depicted by the stronger of the two data sets (see Hillis, 1987). The area cladogram based on the combined data tree (Fig. 10) reflects the pattern shown by the area cladogram based on the molecular tree (Fig. 7) with the exception of the placement of Sulphur Springs and of Bahamas + Chortis Block, which are not sister areas.

\section{Comparison with Xiphophorus and Heterandria}

Rosen $(1978,1979)$ documented congruence of area relationships between two poeciliid fish genera of Middle America (Xiphophorus and Heterandria) after deletion of unique area components and components that were incongruent because only one group possesses endemic taxa in certain areas. Later investigations of Rosen's data have shown that Rosen's incongruent components were largely due to the presence of a few widespread taxa (e.g., Platnick, 1981; Page, 1989). In addition, it

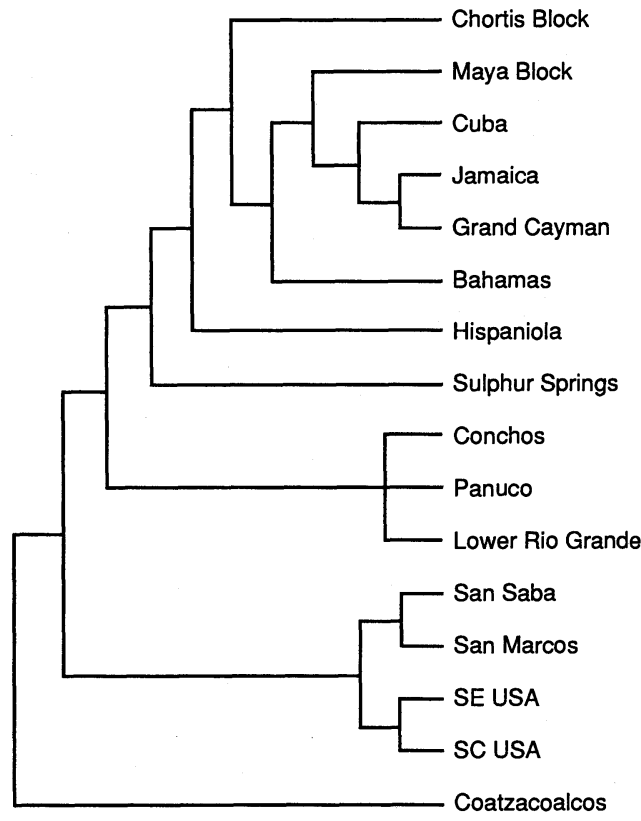

FIGURE 10. A strict consensus tree of the three most optimal area cladograms computed from a heuristic search of the Gambusia combined tree 3. This tree represents the most informative set of area relationships found from the analysis of the six equally parsimonious trees based on the combined morphological and molecular data.

has been shown that the relationships of areas containing widespread taxa reflect the patterns indicated by the taxa endemic to those areas (Page, 1989, 1994). An Adams consensus tree of the three area cladograms supported by both Xiphophorus and Heterandria is shown in Figure 11. This tree is the same tree presented by Platnick (1981) and Page (1989) based on assumption 2 and by Page (1994) using his optimality method.

How do the area cladograms computed from the Gambusia data compare with the area relationships exhibited by the congruent area cladograms of Xiphophorus and Heterandria? The three genera only share the North America, Chortis Block, Maya Block, and Panuco components. For Gambusia, North America can be broken down into several components: SE USA, SC USA, Lower Rio Grande, San Marcos, San Saba, and Conchos. The North American Heterandria representative ( $H$. formosa) is 


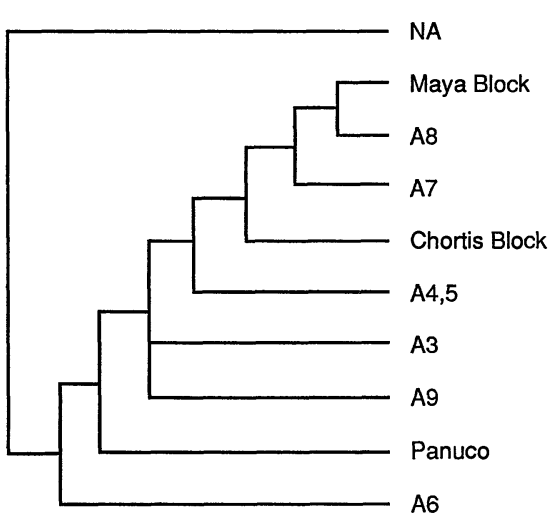

FIGURE 11. A strict consenus tree of the three most optimal trees found from the analysis of two Middle American fish genera, Xiphophorus and Heterandria. This general area cladogram reflects the congruent pattern exhibited by the two taxa. NA = North America. Areas A3, A4,5, A6, A7, A8, and A9 refer to narrow areas of endemism in southern Mexico and Central America based on the distribution of Xiphophorus and Heterandria species (see Rosen, 1979, for details).

found in SE USA, and the North American Xiphophorus representatives (X. gordani and $X$. couchianus) are found in the Lower Rio Grande. The area cladogram of Heterandria + Xiphophorus (Fig. 11) depicts the pattern (North America(Panuco(Maya, Chortis))). However, the two area cladograms based on the molecular and morphological Gambusia data render Rosen's (1978, 1979) North American component paraphyletic, with the Lower Rio Grande more closely related to Panuco than to other North American areas of endemism. The area cladograms of Heterandria, Xiphophorus, and Gambusia agree on the Maya Block and Chortis Block being sister areas.

\section{DISCUSSION \\ Gambusia Phylogeny}

Congruence between phylogenetic hypotheses generated from independent data sets is evidence for considering those hypotheses as representative of the "true" phylogeny for that taxon (e.g., Hillis, 1987). The phylogenetic hypotheses based on the morphological and molecular Gambusia data sets agree in their support for the monophyly of (G. sexradiata, G. eurystoma), (G. marshi, G. panuco), (G. holbrooki, G. af- finis), (G. punctata, G. rhizophorae), (G. oligosticta, G. caymanensis, G. puncticulata), and (G. melapleura, G. wrayi) and share weaker support for the monophyly of the subgenus Arthrophallus (exclusive of $G$. sexradiata, G. eurystoma, and G. hurtadoi) and of the puncticulata species group.

The phylogeny based on the molecular data is different from that based on the morphological data in several ways. The senilis species group is paraphyletic, with G. geiseri as the sister species of $G$. heterochir of the nobilis species group rather than the sister of G. hurtadoi. Gambusia luma is the sister species of all other Gambusia rather than the sister of the Antillean species of the punctata species group. This particular finding is surprising because it requires the independent evolution of eight morphological characters; however, only two of the eight are unique, unreversed synapomorphies (cf. Rauchenberger, 1989). Gambusia rachowi is not the sister species of the panuco species group of the subgenus Heterophallina, but it is the sister of all other Gambusia except G. luma. Gambusia rachowi has been considered by some investigators to be in a separate but closely related genus Heterophallus (Hubbs, 1926; Rivas, 1963; Miller, 1966). Our results provisionally support this taxonomic assignment. Gambusia manni and G. hubbsi, rather than G. hispaniolae and G. hubbsi, appear to be sister taxa. Gambusia yucatana is the sister species to G. oligosticta, G. puncticulata, and $G$. caymanensis but not to any other island forms of the puncticulata species group. Gambusia hispaniolae is the sister species of G. punctata + G. rhizophorae, and $G$. nicaraguensis is the sister species of $G$. manni + G. hubbsi.

Incongruent phylogenetic hypotheses may be due to higher levels of homoplasy in one of the two data sets. The Gambusia morphological and molecular data sets exhibit comparable amounts of homoplasy, with $\mathrm{CI}=0.45$ (based on all characters being assigned equal weight [Lydeard et al., 1995]) and 0.53, respectively, suggesting neither data set is much more homoplastic than the other. Although these are rather low CI values, randomization tests of the 
molecular sequence data (Lydeard et al., 1995) and comparison of these CIs with those generated from random data sets of a comparable number of taxa (Klassen et al., 1991) indicated the presence of significant nonrandom phylogenetic information. Furthermore, low CI values are to be expected given the high number of taxa (Sanderson and Donoghue, 1989).

Incongruence may also be due to the presence of nonindependent characters in the data set (Shaffer et al., 1991). Several of Rauchenberger's (1989) morphological characters are suspect because they are nonindependent and have identical state distributions. For instance, character 26 (high number of segments distal to the elbow on ray $4 \mathrm{a}$ of the gonopodium) and character 27 (high number of segments distal to the serrae on ray $4 p$ of the gonopodium) indicate an increase in segmentation number of the gonopodium and may reflect nonindependent ontogenetic development. Characters 26 and 27 are two of three unique, unreversed synapomorphies uniting G. marshi, G. panuco, and G. rachowi. The phylogeny based on the molecular data, however, depicts $G$. rachowi as more basal and not a member of the subgenus Heterophallina (sensu Rauchenberger, 1989). Similarly, character 51 (ray 5a hook large, schythelike) and character 52 (ray $4 \mathrm{p}$ large, scythelike) may be developmentally linked. Characters 51 and 52 are two of the three unique, unreversed synapomorphies that define the G. punctata $+G$. rhizophorae + G. luma clade. No support for this clade is found however from phylogenetic hypothesis based on the molecular data.

Incongruence may also be due to the use of characters subject to phenotypic plasticity. For instance, Rosen (1960) found that swordtails living in rivers with steep gradients showed reduction in body depth, reduction in number and size of the distal serrae of the gonopodium, and an enlarged "claw" of the gonopodium. At least eight of Rauchenberger's morphological characters (numbers 26, 27, 28, 31, 46, 50, $51,52)$ are related to size and number of spines or segments and may reflect similar trends. In addition, many characters such as the presence or absence of a suborbital bar (number 22) and pigmentation (numbers 21, 24, 49) are considered inconsistent and unreliable (Rivas, 1963, 1969; Fink, 1971a, 1971b). Although these data suggest possible problems with some of the morphological characters, empirical work is needed to determine whether these traits are phenotypically plastic.

Alternatively, problems such as lineage sorting, differential introgression, and site saturation (Avise, 1994) may result in a gene tree for mtDNA that differs from the species tree. Clearly, additional morphological and molecular data are needed to resolve these issues.

\section{Gambusia Area Relationships}

The area cladograms based on both the morphological and molecular data sets each depict similar patterns of area relationships. The drainages of eastern Texas (San Saba and San Marcos) are closely related to the drainages of SE USA + SC USA. The Lower Rio Grande, however, is more closely related to the Panuco basin than to other North American drainages. The remaining North American area of endemism (Conchos) of the Rio Grande basin is closely related to drainages of eastern Texas in the morphological analysis; however, in the molecular analysis, it is closely related to the Panuco and Lower Rio Grande. Rauchenberger's (1989) analysis of other Gambusia species from Conchos (G. senilis, G. alvarezi) supports the findings from the molecular data. However, sequence data are needed to independently corroborate this hypothesis. Faunal similarity data suggest the Conchos is most similar to the other Rio Grande drainages (Smith and Miller, 1986).

Rosen $(1978,1979)$, based on his study of Xiphophorus and Heterandria, hypothesized that the Panuco basin is more closely related to nuclear Central America than to North America. Our Gambusia data do not support this hypothesis. This incongruence does not necessarily falsify Rosen's vicariance explanation. The incongruent cladograms may be due to dispersal of the incongruent taxa or may be a response to 
a different older or younger vicariant pattern. The Panuco basin harbors a fish fauna long recognized as transitional between tropical and temperate types (Darnell, 1962), and it is quite possible that different taxa reflect different patterns of area relationships. Alternatively, other possible taxon cladograms have been described for Xiphophorus (Meyer et al., 1994) and are now being examined in greater detail (Lydeard and Meyer, unpubl. data). Many other fishes are found in this coastal lowland track (Miller and Smith, 1986). We are presently collecting data from these other fishes.

Rosen (1975) and Savage (1982) proposed a vicariance model for the Caribbean based on a synthesis of geologic and ichthyofaunal and herpetofaunal distributional patterns, respectively. They believed their model could serve as the phylogenetic pattern most elements of the biota might exhibit once cladistic analyses were performed. Their model is (West Indies(North America(Panuco, nuclear Central America))). Although more complex vicariance models have been subsequently proposed (Rosen, 1985; Guyer and Savage, 1986), these later models still reflect the antiquity of the West Indies component and the early time of separation from the mainland (late Cretaceous-early Eocene). None of the area cladograms of Gambusia depict the Greater Antillean taxa as the most basal group. Instead, the Greater Antillean taxa appear to be more closely related to taxa from the Maya-mainland source or the Maya + Chortis-mainland source of nuclear Central America (sensu Rosen, 1978). The pattern exhibited by Gambusia suggests a later arrival on the Antilles, which supports a dispersal rather than a vicariance hypothesis. Additional support for a dispersal hypothesis comes from the puncticulata species group. Unlike the majority of Gambusia species, none of the Antillean members of this species group possess a morphologically unique gonopodium. This and additional morphological evidence led Fink (1971a) to suggest that the members of this particular species group are probably only subspecies. The percent se- quence difference among members of the closely related clade of G. yucatana (Maya Block), G. oligosticta (Jamaica), G. caymanensis (Grand Cayman), and G. puncticulata (Cuba) ranges from $1.0 \%$ to $2.8 \%$, which are the lowest interspecific levels reported for the genus (the average among species of Gambusia is 9.1\%; Lydeard et al., 1995).

Vicariance may be a possible mechanism to explain the distributional pattern of the Antillean members of the punctata species group and nicaraguensis species group. Unlike the puncticulata species group, the island taxa exhibit percent sequence differences from the mainland taxa of $8.4 \%$ or more. Unfortunately, we do not have sequence data from all the members of this group, which would allow for a more elaborate comparison between a mobilist's geologic hypothesis and a stabilist's geologic/ taxon dispersal hypothesis (sensu Liebherr, 1988).

\section{CONCLUSIONS}

The phylogenetic hypotheses based on the morphological and molecular data sets exhibit points of congruence and incongruence. Areas of congruence suggest that the underlying historical pattern has been found; areas of incongruence may be due to phenotypic plasticity or the lack of functional or developmental independence in some of the morphological characters. Alternatively, the somewhat limited molecular data may not adequately represent the true phylogeny. We are presently obtaining additional sequence data from other genes.

The Caribbean basin is considered one of the most geologically complex regions in the world. An understanding of the history of the Caribbean requires rigorous analysis of carefully selected data for different taxa (Page and Lydeard, 1994) and construction of area cladograms.

\section{ACKNOWLEDGMENTS}

We thank Craig Guyer, Roderic Page, Lynne Parenti, Michael H. Smith, Patricia J. West, and two anonymous reviewers for their constructive comments on this and/or an earlier draft of the manuscript. We especially thank $R$. Page for providing expertise on the use of COMPONENT and beneficial comments and discussion. Reeve Bailey, Tony Echelle, David Green- 
field, Craig Guyer, Robert Miller, Mary Rauchenberger, and Michael L. Smith generously shared their knowledge of Gambusia and/or West Indies biogeography. David Hernandez, Clark Hubbs, Dominic Isla, Bill Loftus, Bob McKeand, Jim Robinson, Carlos Rodriguez, and Buck Snelson kindly provided specimens for this study. This study would not have been possible without the help of Colin Higgs, Director of Fisheries, Nassau, Bahamas; Oswell Rankine, Office of the Principal Secretary Education, Environment, Recreation, and Culture, Grand Cayman; Roy Moo-Young, Ministry of Agriculture, Fisheries Division, Jamaica; Fisheries Administrator, Belize; Dra. Graciela De La Garza Garcia, Direccion De Flora y Fauna Silvestres, Mexico; and Guillermo Canessa Mora, Direccion General De Vida Silvestre, Costa Rica; who granted collecting permits. This research was funded by an NSF Dissertation Improvement Grant (BSR-90012258 to C.L. and M.C.W.), the Donn E. Rosen Fund of the American Museum of Natural History (grant to C.L.), a grant in aid of research from Sigma $\mathrm{Xi}_{\mathrm{i}}$ (to C.L.), contract DE-AC09-76SROO-819 at the University of Georgia Savannah River Ecology Laboratory (to C.L.), the Alabama Agricultural Experiment Station (AAES no. 15-923238 to M.C.W.), and an NSF grant (BSR9119867 to A.M.). DNA sequences have been deposited in GenBank under accession nos. X1-X25.

\section{REFERENCES}

AvISE, J. C. 1994. Molecular markers, natural history, and evolution. Chapman and Hall, New York.

BlEDSOE, A. J., AND R. J. RAIKOW. 1990. A quantitative assessment of congruence between molecular and non-molecular estimates of phylogeny. J. Mol. Evol. 30:247-259.

BRIGGS, J. C. 1984. Freshwater fishes and biogeography of Central America and the Antilles. Syst. Zool. 33:428-435.

BuRGESS, G. H., AND R. FRANZ. 1989. Zoogeography of the Antillean freshwater fish fauna. Pages 263304 in Biogeography of the West Indies (C. A. Woods, ed.). Sandhill Crane Press, Gainesville, Florida.

BussING, W. A. 1976. Geographic distribution of the San Juan ichthyofauna of Central America with remarks on its origin and ecology. Pages 157-175 in Investigations of the ichthyofauna of Nicaraguan Lakes (E. B. Thorson, ed.). Univ. Nebraska Press, Lincoln.

Bussing, W. A. 1985. Patterns of distribution of the Central American ichthyofauna. Pages 453-473 in The Great American biotic interchange (F. G. Stehli and S. D. Webb, eds.). Plenum, New York.

CONSTANTZ, G. D. 1989. Reproductive biology of poeciliid fishes. Pages 33-50 in Ecology and evolution of livebearing fishes (Poeciliidae) (G. K. Meffe and F. F. Snelson, Jr., eds.). Prentice-Hall, Englewood Cliffs, New Jersey.

DARNELL, R. M. 1962. Fishes of the Rio Tamesi and related coastal-lagoons in east-central Mexico. Publ. Inst. Mar. Sci. Univ. Tex. 8:299-365.

ESTABROOK, G. F., F. R. MCMORRIS, AND C. A. MEACHAM. 1985. Comparison of undirected phyloge- netic trees based on subtrees of four evolutionary units. Syst. Zool. 34:193-200.

FELSENSTEIN, J. 1985. Confidence limits on phylogenies: An approach using the bootstrap. Evolution 39:783-791.

FINDEN, C. R., AND A. D. GoRdON. 1985. Obtaining common pruned trees. J. Classif. 2:255-276.

FINK, W. L. 1971a. A revision of the Gambusia puncticulata complex (Pisces: Poeciliidae). Publ. Gulf Coast Res. Lab. Mus. 2:11-46.

FINK, W. L. 1971b. A revision of the Gambusia nicaraguensis species group (Pisces: Poeciliidae). Publ. Gulf Coast Res. Lab. Mus. 2:47-77.

GuYer, C., AND J. M. SAVAGE. 1986. Cladistic relationships among anoles (Sauria: Iguanidae). Syst. Zool. 35:509-531.

HILLIS, D. M. 1987. Molecular versus morphological approaches to systematics. Annu. Rev. Ecol. Syst. 18: 23-42.

HuBBS, C. 1926. Studies of the fishes of the order Cyprinodontes. VI. Misc. Publ. Mus. Zool. Univ. Mich. 16:1-86.

HumPHRIES, C. J., AND L. R. PARENTI. 1986. Cladistic biogeography. Clarendon Press, Oxford, England.

KlASSEN, G. J., R. D. MoOI, AND A. LOCKE. 1991. Consistency indices and random data. Syst. Zool. 40: 446-457.

KLUGE, A. J. 1989. A concern for evidence and a phylogenetic hypothesis of relationships among Epicrates (Boidae, Serpentes). Syst. Zool. 38:7-25.

KUBICKA, E., G. KUCICKI, AND F. R. MCMORRIS. 1995. An algorithm to find agreement subtrees. J. Classif. (in press).

LEE, D. S., C. R. GILbERT, C. H. HocutT, R. E. JENKINS, D. E. MCAllister, AND J. STAUfFer, JR. (eds.). 1980. Atlas of North American freshwater fishes. North Carolina State Museum of Natural History, Raleigh.

LIEBHERR, J. K. 1988. General patterns in West Indian insects, and graphical biogeographic analysis of some circum-Caribbean Platynus beetles (Carabidae). Syst. Zool. 37:385-409.

LYDEARD, C., M. C. WOOTEN, AND A. MEYER. 1995. Cytochrome $b$ sequence variation and a molecular phylogeny of the livebearing fish genus Gambusia (Cyprinodontiformes: Poeciliidae). Can. J. Zool. (in press).

MeYer, A., J. M. Morrissey, AND M. SChartL. 1994. Recurrent origin of a sexually selected trait in $\mathrm{X} i$ phophorus fishes inferred from a molecular phylogeny. Nature 38:539-542.

MiCKEVICH, M. F. 1978. Taxonomic congruence. Syst. Zool. 27:143-158.

MiCKEVICH, M. F., AND J. S. FARRIS. 1981. The implications of congruence in Menidia. Syst. Zool. 30:351370.

MiCKEVICH, M. F., AND M. S. JoHNSON. 1976. Congruence between morphological and allozyme data in evolutionary inference and character evolution. Syst. Zool. 25:260-270.

MilleR, R. R. 1966. Geographical distribution of Central American freshwater fishes. Copeia 1966:773802.

MilleR, R. R., AND M. L. SMITH. 1986. Origin and 
geography of the fishes of Central Mexico. Pages 487-517 in The zoogeography of North American freshwater fishes (C. H. Hocutt and E. O. Wiley, eds.). Wiley and Sons, New York.

Miуамото, M. M. 1983. Frogs of the Eleutherodactylus rugulosus group: A cladistic study of allozyme, morphological, and karyological data. Syst. Zool. 32:109-124.

Mrүaмото, M. M. 1985. Consensus cladograms and general classifications. Cladistics 1:186-189.

MYERS, G. S. 1966. Derivation of the freshwater fishes of Central America. Copeia 1966:766-773.

Nelson, G., AND N. PlatNiCK. 1981. Systematics and biogeography: Cladistics and vicariance. Columbia Univ. Press, New York.

PAGE, R. D. M. 1988. Quantitative cladisitic biogeography: Constructing and comparing area cladograms. Syst. Zool. 37:254-270.

PAGE, R. D. M. 1989. Comments on component-compatibility in historical biogeography. Cladistics 5: 167-182.

PAGE, R. D. M. 1990a. Component analysis: A valiant failure? Cladistics 6:119-136.

PAGE, R. D. M. 1990b. Temporal congruence and cladistic analysis of biogeography and cospeciation. Syst. Zool. 39:205-226.

PAGE, R. D. M. 1993. COMPONENT, version 2.0. The Natural History Museum, London.

PAGE, R. D. M. 1994. Maps between trees and cladistic analysis of historical associations among genes, organisms, and areas. Syst. Biol. 43:58-77.

PAGE, R. D. M., AND C. LYDEARD. 1994. Towards a cladistic biogeography of the Caribbean. Cladistics 10:21-41.

PlATNICK, N. 1981. Widespread taxa and biogeographic congruence. Pages 223-227 in Advances in cladistics, Volume 1 (V. A. Funk and D. R. Brooks, eds.). New York Botanical Garden, New York.

Platnick, N., AND G. Nelson. 1978. A method of analysis for historical biogeography. Syst. Zool. 27: 159-188.

RAUCHENBERGER, M. 1988. Historical biogeography of poeciliid fishes in the Caribbean. Syst. Zool. 37: 356-365.

RAUCHENBERGER, M. 1989. Systematics and biogeography of the genus Gambusia (Cyprinodontiformes: Poeciliidae). Am. Mus. Novit. 2951:1-74.

RivAS, L. R. 1963. Subgenera and species groups in the poeciliid fish genus Gambusia Poey. Copeia 1963: 331-347.

RIVAS, L. R. 1969. A revision of the poeciliid fishes of the Gambusia punctata species group, with descriptions of two new species. Copeia 1969:778-795.

RIVAS, L. R. 1986. Comments on Briggs (1984): Freshwater fishes and biogeography of Central America and the Antilles. Syst. Zool. 35:633-639.

RosEN, D. E. 1960. Middle-American poeciliid fishes of the genus Xiphophorus. Bull. Fla. State Mus. 5:58242.

ROSEN, D. E. 1975. A vicariance model of Caribbean biogeography. Syst. Zool. 24:431-464.

ROSEN, D. E. 1978. Vicariant patterns and historical explanation in biogeography. Syst. Zool. 27:159-188.

ROSEN, D. E. 1979. Fishes from the upland and intermontane basins of Guatemala: Revisionary studies and comparative geography. Bull. Am. Mus. Nat. Hist. 162:267-376.

ROSEN, D. E. 1985. Geological hierarchies and biogeographic congruence in the Caribbean. Ann. Mo. Bot. Gard. 72:636-659.

RoSEN, D. E., AND R. M. BAILEY. 1963. The poeciliid fishes (Cyprinodontiformes), their structure, zoogeography, and systematics. Bull. Am. Mus. Nat. Hist. 126:1-176.

SANDERSON, M. J., AND M. J. DONOGHUE. 1989. Patterns of variation in levels of homoplasy. Evolution 43:1781-1795.

SAVAGE, J. M. 1982. The enigma of the Central American herpetofauna: Dispersal or vicariance? Ann. Mo. Bot. Gard. 69:464-547.

Shaffer, H. B., J. M. Clark, AND F. KRAus. 1991. When molecules and morphology clash: A phylogenetic analysis of the North American ambystomatid salamanders (Caudata: Ambystomatidae). Syst. Zool. 40:284-303.

SMITH, M. L., AND R. R. MilleR. 1986. The evolution of the Rio Grande Basin as inferred from its fish fauna. Pages 457-485 in The zoogeography of North American freshwater fishes (C. H. Hocutt and E. O. Wiley, eds.). Wiley and Sons, New York.

SWOFFORD, D. L. 1991. When are phylogeny estimates from molecular and morphological data incongruent? Pages 295-333 in Phylogenetic analysis of DNA sequences (M. M. Miyamoto and J. Cracraft, eds.). Oxford Univ. Press, New York.

SwOFFORD, D. L. 1993. PAUP: Phylogenetic analysis using parsimony, version 3.1. Illinois Natural History Survey, Champaign.

Received 4 March 1993; accepted 15 August 1994 
APPENDIX 1. The proposed classification of Gambusia based on the work of Rauchenberger (1989) and the distribution of the taxa (see Fig. 6) used in the present study (see Rauchenberger [1989] for more detailed distributional data of each species). An asterisk denotes species examined in the present study.

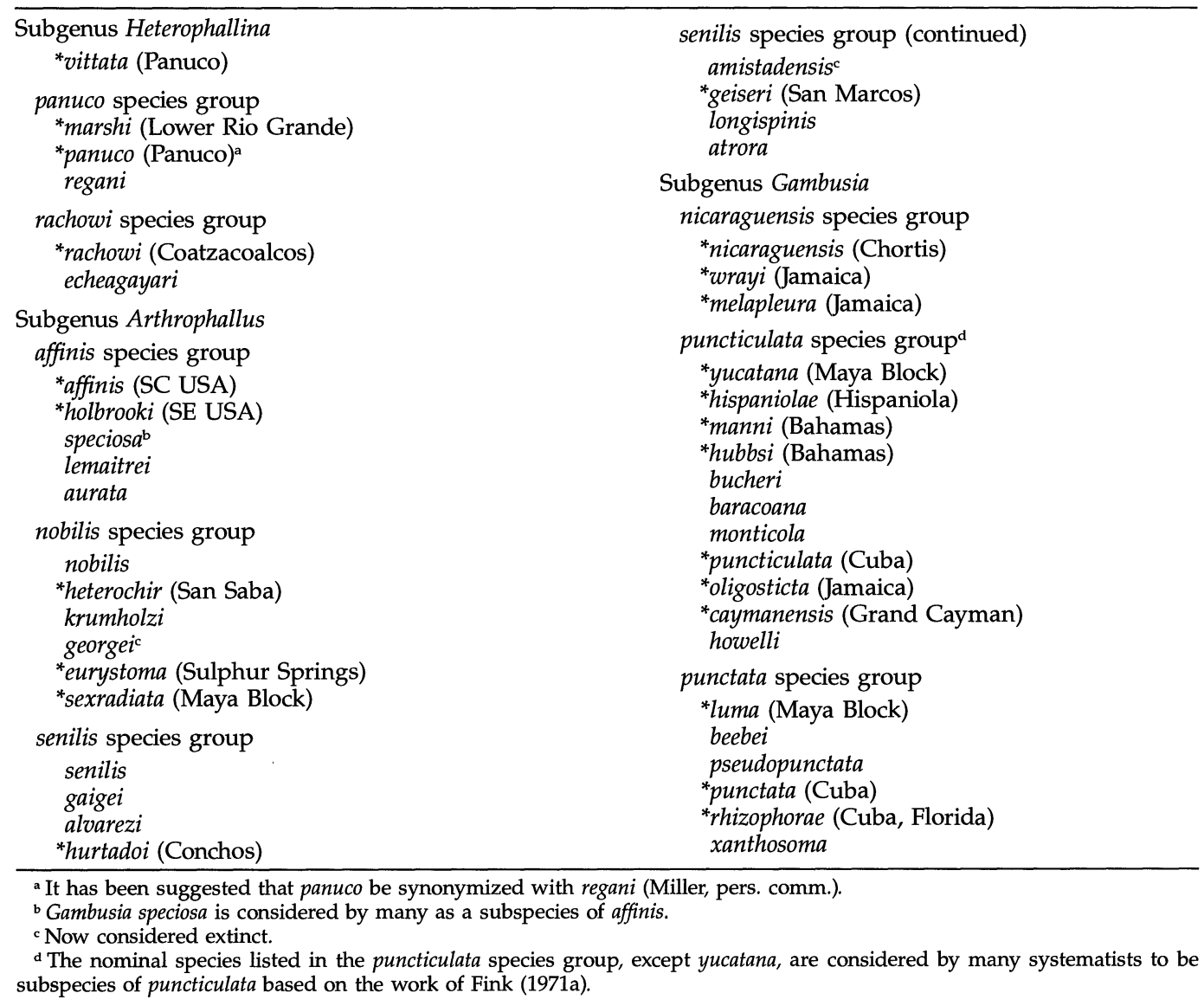


APPENDIX 2. Morphological data matrix for Gambusia and the outgroup modified from that of Rauchenberger (1989).

\begin{tabular}{|c|c|}
\hline & Characters \\
\hline Taxon & $\begin{array}{r}1111111112222222222333333333344444444445555555556666 \\
7890123457890123456789012345678901234567890123567890123\end{array}$ \\
\hline Belonesox belizanus & 0000000000000000000000000000000000000000000000000000000 \\
\hline G. vittata & 1111111000000001000000000000000000010009009000900000900 \\
\hline G. marshi & 1111111000000001011111100000000000010009099000900000900 \\
\hline G. panuco & 1111110000000101011111111000000000010009099000900090900 \\
\hline G. rachowi & 1111111000001001011100001111110000020009099000900090900 \\
\hline G. affinis & 1111100100001112200000000000000022200000009000910012010 \\
\hline G. holbrooki & 1111100100001112200000000000000011100000099000910001010 \\
\hline G. heterochir & 1111100100109011200000121000001100020001099000900099900 \\
\hline G. eurystoma & 1111100000000111900000002000001100010001099000900090000 \\
\hline G. sexradiata & 1111100000000110900000002000001100010001099000900092000 \\
\hline G. geiseri & 1111100100002001200000110000001100000112099000900093100 \\
\hline G. hurtadoi & 1111100100001010100000000000001100100112199000900010100 \\
\hline G. nicaraguensis & 1111100010120112100000100000000000000000000000000090000 \\
\hline G. wrayi & 1111100011120111100000100000000000000000000000000093001 \\
\hline G. melapleura & 1111100011129111100000100000000000000000000000000099001 \\
\hline G. yucatana & 1111100011100111000000101000000100100001100000000193000 \\
\hline G. hispaniolae & 1111100011111101000000001000000000100001110000000191000 \\
\hline G. manni & 1111100011111101000000001000000000100001110000000199000 \\
\hline G. hubbsi & 1111100011111111000000001000000100100001110000000191100 \\
\hline G. puncticulata & 1111100011110112100000001000000100100001110000000192100 \\
\hline G. oligosticta & 1111100011110112100000001000000100100001110000000199100 \\
\hline G. caymanensis & 1111100011110112100000001000000100100001110000000199100 \\
\hline G. luma & 1111100021000110000000002000000100000002000110000001000 \\
\hline G. punctata & 1111100021110100000000001000000100000002200111001092000 \\
\hline G. rhizophorae & 1111100021010100000000002000000100000002200111101022000 \\
\hline
\end{tabular}

